\title{
Uma análise da pressão no trabalho, da liberdade e do apoio social entre servidores de um tribunal
}

\author{
Rogério Rodrigues da Silva \\ Instituto Superior de Economia e Gestão da Universidade Técnica de Lisboa
}

\begin{abstract}
O artigo aborda a questão do estresse entre servidores de um tribunal, por meio da análise da pressão no trabalho, do nível de liberdade na atividade e do apoio social. Foi aplicada a escala reduzida job stress scale, validada para o Brasil. Participaram do estudo 131 homens e 134 mulheres, todos servidores públicos concursados. Os resultados apontam para três questões. A primeira é que há uma moderada percepção de pressão e de liberdade no trabalho dos servidores. Uma segunda aponta para as ótimas relações entre colegas e chefia no trabalho, independente de gênero ou do cargo ocupado. A última está relacionada ao fato de que a pressão no trabalho, embora moderada, é maior entre os gerentes, que estão mais sujeitos aos jogos políticos e de poder na instituição, em comparação aos que não ocupam essa posição.
\end{abstract}

Palavras-chave: Estresse, Servidores públicos, Judiciário.

An analysis of the pressure at work, the liberty and the social support in servants of a court of justice

The article is concerned with the level of stress in servants of a court of justice, through the analysis of the pressure at work, the level of liberty at work and the social support. The instrument applied was the job stress reduced scale, validated in Brazil. The questionnaires were administrated to 131 men and 134 women. The results point to three questions. The first is that there is a moderated level of pressure and liberty perception at work. The second points to excellent relationship among partners and managers, which is independent of gender and the position occupied. The last one points to the fact that the pressure at work, although moderated, is higher in managers, who are more liable to the political and power games of the organization than those who do not occupy this position.

Keywords: Stress, Public servants, Judiciary.

administração pública vem adotando, em um cenário de constantes transformações
pociais e econômicas, medidas que aumentariam a eficiência e a eficácia nas organizações
entre outras (Seabra, 2001). Sob essa perspectiva, a atividade do servidor público - comumente
associada a uma burocracia incompetente, caracterizada pelo formalismo ineficaz, por um
trabalho lento, irracional e pouco eficiente (Hegedus, 1996) - transforma-se em um trabalho
que requer resultados cada vez mais rápidos e objetivos. Todavia, no caso brasileiro, algumas
questões como estrutura e cultura organizacional, como aponta Seabra (2001), ainda emperram
o avanço de um modelo burocrático tradicional para um modelo gerencial que possibilite a
flexibilidade de procedimentos e um maior controle dos resultados.

Reza Osborne (1995) que transformar burocracias públicas em governos empreendedores, produtivos e eficientes tem uma relação estreita com o ceticismo do cidadão sobre a capacidade do Estado em administrar a sociedade e satisfazer suas crescentes e complexas necessidades sociais. Segundo o autor, o mau não está nas pessoas ou nos servidores públicos, mas nos sistemas, nas estruturas, nas regras e nos procedimentos que impedem a capacidade criativa do trabalhador e emperram a máquina produtiva.

O desequilíbrio entre uma administração rígida e obsoleta - que enfatiza a adesão, quase que incondicional, a regras e procedimentos em detrimento da adesão à renovação, à 
flexibilidade, à criatividade - pode ter efeitos devastadores para as organizações, mas, sobretudo, para os próprios trabalhadores (Seabra, 2001). Um desses efeitos é o aumento do nível de estresse entre os servidores públicos (Barcelos Silva, 2004; Lipp \& Tanganelli, 2002; Tavares, 2003).

Estudos realizados com médicos, juízes, bancários, atendentes, todos servidores públicos, mostram que há uma grande incidência de estresse nessa categoria (Lipp \& Tanganelli, 2002; Minari, 2007). Segundo esses estudos, algumas das consequências da alta incidência de estresse são: falta de confiança no trabalho; mau desempenho no trabalho; falta de sono; dores de cabeça constantes; dificuldades em relacionamentos sociais. Diante desse quadro, parece-nos que, a despeito da estabilidade financeira, tão almejada por muitos, a categoria dos servidores também sofre com a instabilidade psíquica e orgânica desencadeada também pelo estresse no trabalho.

Um modelo bastante adotado tanto nacional, quanto internacionalmente, segundo Araújo, Graça e Araújo (2003), para estudar a questão do estresse no trabalho é o de Karasek e Theorell (1990). Esse modelo privilegia uma análise psicossocial do trabalho e contribui para a análise dos riscos a saúde física e psicológica dos trabalhadores. O modelo pauta-se pela análise de três variáveis, quais sejam: pressão no trabalho, liberdade no trabalho e apoio social. Desse modo, o presente estudo tem um caráter exploratório e, ainda, objetiva discutir a relação da ocorrência das variáveis supracitadas e o estresse no trabalho em um grupo de servidores de um tribunal do Distrito Federal.

\section{O servidor do Judiciário}

O modelo que se observa nas organizações públicas, denominado por Chanlat (1996) de tecnoburocrático, caracteriza-se, segundo Osborne (1995): pela disciplina hierárquica, que ofusca a competência técnica; pela concentração de decisões de poder e autoridade; pela ênfase na despersonalização dos relacionamentos pessoais; pelo formalismo técnico, que mina as possibilidades de criação e de reinvenção necessárias no trabalho; e, por fim, pela má alocação de funcionários. Tudo isso mantém, segundo Durand e Beltrão (1994), relações estreitas com a ocultação de problemas, contradições e desequilíbrios observados na gestão pública. Esses condicionantes geram uma crise no Estado e também no funcionalismo público, perpetuandose como um círculo vicioso. O Estado é mal gerido e os funcionários gerem e são igualmente mal geridos.

Esse modelo desvaloriza o funcionário, rompe com sua identidade pessoal, limita a ação humana criativa daqueles que com ele lidam e favorece insatisfação, doenças físicas e mentais, como, por exemplo, Ler/Dort, depressão, alcoolismo (Bogg \& Cooper, 1995; Chanlat, 1996; Silva \& Holanda, 2008). Além disso, a carga maior de trabalho, o valor da hora de trabalho menos valorizada (na maioria das categorias e em relação à iniciativa privada), as condições precárias de trabalho e a falta de oportunidade de crescimento na carreira podem ainda potencializar os efeitos maléficos sobre a saúde física e mental dos servidores públicos.

No Judiciário, esse cenário caótico não é diferente. A crescente demanda judicial, atrelada a ritos processuais ultrapassados, e a identidade profissional e pessoal abaladas pela desvalorização social decorrente de preconceitos constituem-se como sérias ameaças a saúde física e mental dos servidores desse poder (Sadek \& Arantes, 1994). Para se ter uma ideia, segundo Barcelos Silva (2004), baseado em dados fornecidos pelo Banco Nacional de Dados do Poder Judiciário, houve um aumento, entre 1989 e 2001, de 568\% no número de processos distribuídos para os Tribunais Regionais Federais. No que tange à saúde dos servidores, o autor 
afirma que houve um aumento de mais de 1000\% no número de casos de Ler/Dort entre os servidores do Judiciário entre 1982 e 1998.

Biancamano (1999), em estudo sobre um tribunal de Porto Alegre (RS), aponta que há uma alienação cada vez maior no processo organizacional, principalmente porque o servidor é pouco estimulado a participar das tomadas de decisões e da vida organizacional. A situação funcional também dá abrigo e sustenta esse servidor desmotivado e desestimulado pela organização, uma vez que está "protegido" de qualquer responsabilidade por sua nãoparticipação e por uma ausência quase total de instrumentos de acompanhamento individual de sua trajetória funcional. Para a autora, a exacerbação do enfoque burocrático impede servidores, e até magistrados, de pensarem por si próprios, de terem maiores níveis de criação, inovação e eficácia, o que emperra um maior desenvolvimento organizacional e pessoal.

Em estudo no Tribunal Regional Federal paulista, Bellusci e Fischer (1999) apontam que os principais fatores organizacionais e psicossociais responsáveis pelo desgaste no trabalho são: dificuldade de relacionamento interpessoal, falta de perspectiva de ascensão profissional, exigências excessivas da quantidade e da qualidade do trabalho. Nessa mesma perspectiva, Garbin e Tavares (2000) afirmam que as principais causas de desgaste e frustração dos servidores do Judiciário estão ligadas à impossibilidade de planejamento da carreira, à inconsistência de critérios de promoção, à ingerência e à centralização de poder. Segundo Barcelos Silva (2004), não apenas entre os servidores do Judiciário, mas até entre os magistrados, as principais causas da falta de motivação estão ligadas à ausência de informações completas e detalhadas, de feedback, de reconhecimento no trabalho e de liberdade para participação na organização.

Tavares (2003), em estudo em um tribunal federal paulista, afirma ainda que, diante de vários elementos estressores, como a falta de autonomia, o não reconhecimento pelo trabalho, a injustiça no ambiente de trabalho, a estagnação profissional, os servidores utilizam alguns moderadores para lidar com o sofrimento no trabalho, quais sejam: o distanciamento afetivo, o descumprimento do trabalho, a busca de progressão baseada exclusivamente em relacionamentos pessoais e o investimento em dimensões que estão fora do trabalho.

Diante do exposto, pode-se afirmar que o desequilíbrio entre a busca por produção e eficiência e a falta de motivação por desafios, inovação, valorização e participação nas decisões da vida organizacional podem criar condições para uma séria deterioração do estado de saúde física e mental dos servidores do Judiciário. Nesse sentido, qual seria o papel da pressão no trabalho, da liberdade para a execução das atividades e do apoio social para o desequilíbrio psíquico vivido pelos servidores? É isso que aborda o presente estudo.

\section{Abordagens de estresse ocupacional e o modelo adotado}

O crescente interesse pelo estudo do estresse no trabalho nos últimos anos deve-se principalmente ao seu impacto negativo na saúde e no bem-estar dos empregados e, consequentemente, no funcionamento e na efetividade das organizações. Esse impacto baseiase no fato de que trabalhadores estressados diminuem seu desempenho e aumentam os custos das organizações com problemas de saúde, com o aumento do absenteísmo, com a rotatividade e com acidentes no local de trabalho (Paschoal \& Tamayo, 2005).

Para Rossi (2007) existem dois tipos de abordagem de estudos do estresse no trabalho: a funcional e a disfuncional. $\mathrm{Na}$ abordagem funcional, à medida que os estímulos de estresse aumentam, o desempenho do indivíduo também tende a aumentar, o que seria uma resposta positiva aos estímulos estressores, todavia, quando os estímulos são muito intensos, o 
desempenho do indivíduo começa a cair. Já na abordagem disfuncional, o estresse está ligado a um desequilíbrio na homeostasia psicológica ou fisiológica dos indivíduos, que ocorre quando o indivíduo é forçado a enfrentar situações que ultrapassam sua habilidade de enfrentamento, embora nem todos reajam da mesma maneira (Rossi, 2007). Se os estressores persistem e se os sujeitos percebem seu enfrentamento como insuficientes podem, então, produzir reações de estresse psicológico e físico, o que pode gerar doenças como o alcoolismo e a depressão. Para o presente estudo será considerada essa última abordagem.

Por ser assim complexo, o estresse pode estar relacionado a diversos fatores, sejam eles de natureza individual ou organizacional. Ferris et al. (2007) afirmam que as principais variáveis moderadoras/mediadoras do processo de estresse no nível individual estão ligadas ao lócus de controle, à participação na tomada de decisões, ao apoio social do supervisor, ao grau de comprometimento organizacional e à capacidade de realização de tarefas (vistas como desafios e não como ameaças).

Quanto aos aspectos organizacionais que influenciam os níveis de estresse, Stacciarini e Trócoli (2002) classificam os principais estressores em seis grandes grupos: fatores intrínsecos do trabalho (condições inadequadas, turnos e carga horária de trabalho, novas tecnologias), papéis estressores (ambíguos, conflituosos), relações no trabalho, estressores na carreira (falta de desenvolvimento, insegurança no trabalho), estrutura organizacional (estilos de gerenciamento, falta de participação, estilos de comunicação) e interface trabalho-casa.

Uma outra característica organizacional relacionada também ao estresse é a política (Ferris et al., 2007; Nelson \& Simons, 2007). Isso se deve a seu caráter tipicamente divisor e, acima de tudo, ilegítimo, já que não é sancionado nem pela autoridade formal, nem por conhecimento certificado. Assim, em ambientes carregados de ambiguidade quanto a análises objetivas de desempenho, como é o serviço público, a política pode configurar-se como um fator estressor.

Para fins desta pesquisa foi eleito o modelo de Karasek e Theorell (1990) de análise do estresse. Esse modelo avalia a questão do estresse por meio da análise, segundo Araújo, Graça e Araújo (2003), de três fatores: demanda, controle e apoio social.

Demanda é definida por Karasek e Theorell (1990) como as pressões de natureza psicológica, sejam elas quantitativas, tais como tempo e velocidade, ou qualitativas, como os conflitos entre demandas contraditórias para a realização do trabalho. Já o controle é definido como sendo a possibilidade do trabalhador utilizar suas habilidades intelectuais para a realização de seu trabalho, bem como possuir autoridade suficiente para tomar decisões sobre a forma de realizá-lo. Por fim, o apoio social é definido como sendo os níveis de interação social existentes no trabalho, tanto com os colegas quanto com os chefes.

Segundo Karasek e Theorell (1990), há quatro tipos de análise da inter-relação entre as variáveis demanda, controle e apoio social. São elas: alta exigência do trabalho (caracterizado como alta demanda e baixo controle), trabalho ativo (alta demanda e alto controle), trabalho passivo (baixa demanda e baixo controle) e baixa exigência (baixa demanda e alto controle). Segundo Araújo, Graça e Araújo (2003), a principal predição estabelecida aqui é que a maioria das reações adversas das exigências psicológicas, tais como fadiga, ansiedade, depressão e doença física, ocorre quando há alta demanda do trabalho e um baixo grau de controle do trabalhador. Outra inter-relação possível no modelo é que, quando há baixa demanda e baixo controle, há um declínio na atividade global do indivíduo e uma redução da capacidade de produzir soluções para as atividades e os problemas enfrentados. Por outro lado, segundo Alves et al. (2004), quando alta demanda e alto controle coexistem, os indivíduos percebem as demandas como menos danosas, na medida em que o trabalhador pode escolher como planejar suas horas de trabalho e criar estratégias para lidar com suas dificuldades. 
A situação ideal para os trabalhadores, a partir do modelo adotado no estudo, é de baixa demanda e alto controle, o que geraria baixo desgaste, segundo Alves et al. (2004). Isso significa que o trabalhador tem pressão no trabalho, mas, em contrapartida, possui liberdade para decidir e atuar da melhor maneira naquela situação.

\section{Metodologia}

\section{Participantes}

A pesquisa foi realizada com 265 servidores, sendo 131 homens e 134 mulheres. Isso representa perto de $10 \%$ do total de servidores do tribunal onde foi realizado o estudo. A média de idade foi de 39,24 anos ( $\mathrm{DP}=8,895)$ e houve uma concentração maior na faixa dos 30 aos 49 anos de idade (72,4\%). Desses participantes, apenas $24,52 \%$ exerciam algum tipo de gerência. Quanto à distribuição dos participantes por tempo de serviço no tribunal, observou-se a média de 11,20 anos $(\mathrm{DP}=8,16)$.

\section{Instrumentos}

O instrumento utilizado na pesquisa foi a versão reduzida da job stress scale criada por Karasek e Theorell (1990) e validada no Brasil por Alves et al. (2004). A escala é do tipo Likert 4 pontos, composta por 17 itens e pelos 3 fatores anteriormente descritos, quais sejam:

1. Demanda (5 itens e alfa de Crombach de 0,69). Quanto mais próxima ao valor 1 estivesse a média, maior seria a pressão psicológica sobre o trabalho. Um exemplo de item é: Com que frequência você tem que fazer suas tarefas de trabalho com muita rapidez?

2. Controle (6 itens e alfa de Crombach de 0,63). Quanto mais próxima ao valor 1 estivesse a média, maior a possibilidade de usar as habilidades técnicas no trabalho. Exemplo do fator: Você pode escolher como fazer o seu trabalho?

3. Apoio social (6 itens e alfa de Crombach de 0,86). Quanto menor fosse a média, melhor seria o relacionamento entre pares e chefia. Exemplo do fator: Existe um ambiente calmo e agradável onde trabalho.

Os resultados foram avaliados da seguinte maneira: na média do fator entre 1 e 2 (inclusive) há uma vivência forte do fator; na média do fator entre 2 (exclusive) e 3 (inclusive) há uma vivência moderada do fator e na média do fator entre 3 (exclusive) e 4 (inclusive) há uma vivência fraca do fator. Para dicotomização de controle (baixo/alto) e de demanda (baixa/ alta) estabeleceu-se ponto de corte na média, conforme recomendações do Job Content Questionnaire User's Guide, citado por Karasek e Theorell (1990).

\section{Procedimentos}

Os sujeitos foram selecionados utilizando-se o método de amostra aleatória simples, como indicado por Muniz e Abreu (1999), no qual todos os sujeitos têm a mesma probabilidade de compor a amostra.

Os aplicadores (consultores externos, não conhecedores nem conhecidos da organização), a partir de contatos telefônicos prévios com a chefia marcavam a aplicação, dirigiam-se às seções e distribuíam os questionários a todos os servidores que se dispusessem a 
participar da pesquisa. A aplicação ocorreu em todas as seções do órgão, observando a anuência das chefias e dos servidores, bem como todas as questões ergonômicas (luminosidade, sonoridade etc.) e éticas para tal.

\section{Análise dos dados}

A análise dos dados pautou-se em uma análise quantitativa, na qual foram empregadas estatísticas descritivas, análises correlacionais e análises inferenciais, com o auxílio do software SPSS (Statistical Package for Social Science) versão 10.0.

\section{Resultados}

Para uma melhor compreensão dos dados obtidos, os resultados e a discussão apresentados serão divididos por: fatores, gênero e ocupação ou não de gerência.

\section{Análise por fator}

Quadro 1. Médias e prevalências dos fatores analisados $(\mathrm{N}=265)$

\begin{tabular}{|c|c|c|c|c|}
\hline Fator & Média geral & Desvio padrão & Intervalo das médias & Prevalência \\
\hline \multirow{3}{*}{ Demanda } & \multirow{3}{*}{2,2979} & \multirow{3}{*}{0,5562} & $1 \leq$ média $\leq 2$ & $19,62 \%$ \\
\hline & & & $2<$ média $\leq 3$ & $67,18 \%$ \\
\hline & & & $3<$ média $\leq 4$ & $13,20 \%$ \\
\hline \multirow{3}{*}{ Controle } & \multirow{3}{*}{2,2509} & \multirow{3}{*}{0,5424} & $1 \leq$ média $\leq 2$ & $29,43 \%$ \\
\hline & & & $2<$ média $\leq 3$ & $62,64 \%$ \\
\hline & & & $3<$ média $\leq 4$ & $7,9 \%$ \\
\hline \multirow{3}{*}{ Apoio social } & \multirow{3}{*}{1,4862} & \multirow{3}{*}{0,4881} & $1 \leq$ média $\leq 2$ & $87,2 \%$ \\
\hline & & & $2<$ média $\leq 3$ & $12,8 \%$ \\
\hline & & & $3<$ média $\leq 4$ & $0,00 \%$ \\
\hline
\end{tabular}

Os resultados apresentados no Quadro 1 apontam que, de maneira geral, os fatores demanda e controle são moderados e o fator suporte social apresenta uma forte vivência para a maioria do grupo. Isso indica que os servidores percebem a existência de boas relações interpessoais no ambiente de trabalho, tanto com os colegas como com a chefia.

Além disso, os dados apontam que a maioria dos servidores tem uma pressão moderada no trabalho - fator demanda - $(67,18 \%$ dos participantes $)$ e uma moderada possibilidade de utilizar as habilidades intelectuais para a realização das atividades - fator controle - $(29,43 \%$ dos participantes). 
Quadro 2. Prevalência segundo níveis de demanda psicológica e controle sobre o próprio trabalho $(\mathrm{N}=265)$

\begin{tabular}{|l|l|l|l|}
\hline Fatores & Grupos do modelo Karasek \& Theorell & Frequência & Prevalência \\
\hline Demanda alta e controle alto & Trabalho ativo & 44 & $16,60 \%$ \\
\hline Demanda alta e controle baixo & Alta exigência & 12 & $4,52 \%$ \\
\hline Demanda baixa e controle alto & Baixa exigência & 14 & $5,28 \%$ \\
\hline Demanda baixa e controle baixo & Trabalho passivo & 6 & $2,26 \%$ \\
\hline
\end{tabular}

Os resultados do Quadro 2 indicam que apenas 76 pessoas percebem uma pressão alta ou baixa e uma liberdade alta ou baixa. Os outros 189 servidores têm uma percepção moderada desses fatores e não foram analisados, ante o modelo de análise de Karasek e Theorell (1990). Entre os 76 participantes avaliados, observa-se que a maior ocorrência é do grupo onde há demanda alta e controle alto, chamado por Karasek e Theorell (1990) de trabalho ativo. Outro ponto importante a ressaltar é que o grupo onde poderia haver uma incidência maior de reações adversas ao trabalho, tais como fadiga, ansiedade, depressão, caracterizado por uma demanda alta e um controle baixo, tem uma prevalência baixa de apenas 4,52\% dos participantes.

\section{Quadro 3. Itens com maiores médias}

\begin{tabular}{|l|l|l|l|}
\hline Fatores & Itens & Média & Desvio padrão \\
\hline \multirow{3}{*}{ Demanda } & $\begin{array}{l}\text { Com que frequência você tem que fazer suas tarefas de } \\
\text { trabalho com muita rapidez }\end{array}$ & 1,623 & 0,65 \\
\cline { 2 - 4 } & Com que frequência você tem que trabalhar intensamente & 1,789 & 0,76 \\
\hline \multirow{2}{*}{ Controle } & Seu trabalho exige que você tome iniciativas? & 1,555 & 0,76 \\
\cline { 2 - 4 } & $\begin{array}{l}\text { Seu trabalho exige muita habilidade ou conhecimentos } \\
\text { especializados? }\end{array}$ & 1,574 & 0,84 \\
\hline \multirow{2}{*}{ Apoio social } & Eu gosto de trabalhar com meus colegas & 1,277 & 0,51 \\
\cline { 2 - 4 } & No trabalho, eu me relaciono bem com meus chefes & 1,283 & 0,5 \\
\hline
\end{tabular}

A análise dos itens que obtiveram as maiores médias, indicando um conteúdo de maior força e prevalência, exposto no Quadro 3, tal qual o modo de análise apresentado por Silva e Holanda (2008), aponta que a demanda no trabalho está ligada sobretudo à rapidez e à intensidade do trabalho. Nessa mesma análise, os dados apontam que o controle no trabalho está ligado principalmente à iniciativa que se pode ter no trabalho e também à utilização dos conhecimentos nas atividades realizadas. Quanto ao apoio social, os dados apontam haver bons relacionamentos com colegas e também com a chefia.

\section{Análise por gênero}

Para essa verificação de diferenças entre as médias entre homens e mulheres, tal como exposta no Quadro 4 abaixo, foi utilizada a análise de variância ANOVA one-way e o teste t. Não foram, entretanto, verificadas diferenças significativas entre os grupos (demanda $\mathrm{F}(1,263)=0,712$, t $(0,05,263)=0,844-$ controle $\mathrm{F}(1,263)=0,484$, t $(0,05,263)=0,527-$ 
suporte $F(1,263)=0,146, t(0,05,263)=-0,382 ; p<0,05)$. Isso indica que homens e mulheres percebem o mesmo nível de pressão no trabalho, controle e relacionamento interpessoal.

Quadro 4. Distribuição das médias dos fatores entre homens e mulheres e entre gerentes e não gerentes ${ }^{5}$

\begin{tabular}{|l|l|l|l|l|l|l|l|l|}
\hline & \multicolumn{4}{|l|}{ Gênero } & \multicolumn{3}{l|}{ Gerentes } \\
\cline { 2 - 9 } & \multicolumn{3}{|l|}{ Homens $(\mathrm{N}=131)$} & \multicolumn{2}{l|}{ Mulheres $(\mathrm{N}=134)$} & \multicolumn{2}{l|}{ Sim $(\mathrm{N}=64)$} & \multicolumn{2}{l|}{ Não $(\mathrm{N}=197)$} \\
\cline { 2 - 9 } & Média & $\mathrm{DP}$ & Média & $\mathrm{DP}$ & Média & DP & Média & DP \\
\hline Demanda & 2,3271 & 0,5285 & 2,2694 & 0,5826 & 2,0734 & 0,4484 & 2,3746 & 0,5681 \\
\hline Controle & 2,2275 & 0,5324 & 2,2739 & 0,5531 & 2,0234 & 0,3549 & 2,3393 & 0,5655 \\
\hline Apoio social & 1,4746 & 0,4721 & 1,4975 & 0,5048 & 1,5677 & 0,4711 & 1,4695 & 0,4922 \\
\hline
\end{tabular}

\section{Análise por cargo}

Foi realizada a mesma análise ANOVA one-way e o teste $t$ para a verificação de diferenças entre as médias dos gerentes e não gerentes, tal como exposto no Quadro 4.

Quanto ao fator demanda, os dados apontam para uma maior pressão psicológica entre os gerentes em relação aos que não ocupam esse cargo $(F(1,259)=14,949 ; \mathrm{t}(0,05,259)=$ $-3,866 ; \mathrm{p}<0,05)$.

Quanto à possibilidade de aplicar as habilidades intelectuais na realização do trabalho fator controle - os dados apontam uma diferença estatisticamente significativa $(\mathrm{F}(1,259)=$ $17,669 ; \mathrm{t}(0,05,259)=-4,204 ; \mathrm{p}<0,05)$ entre o grupo de gerentes e não gerentes. Isso indica que gerentes e não gerentes não têm a mesma possibilidade de utilizar suas habilidades no trabalho.

Para o fator apoio social, os dados apontam que há uma forte percepção do apoio social tanto entre gerentes e não gerentes, mas não existem diferenças significativas $(F(1,259)=$ $1,961 ; \mathrm{t}(0,05,259)=1,401 ; \mathrm{p}<0,05)$ entre esses grupos. Haveria, assim, níveis semelhantes entre gerentes e não gerentes no tocante às interações sociais estabelecidas com os colegas e a chefia.

\section{Discussão}

O vertiginoso aumento da demanda por serviços do Poder Judiciário acarretou uma carga maior de trabalho a seus servidores (Barcelos Silva, 2004). Isso não traria grandes implicações caso houvesse um aumento proporcional no quadro de servidores, bem como a modernização dos sistemas informacionais utilizados na Justiça. Todavia, o que se observa é a estagnação do número de servidores e da infraestrutura ofertada, o que pode trazer reflexos nas queixas dos servidores quanto à frequência e à intensidade do trabalho como sendo os principais itens que contribuem para a pressão no trabalho, como indicado no Quadro 3. No caso do tribunal pesquisado, há de se dizer que por ser órgão central para todo o Judiciário, os investimentos na área de tecnologia da informação (sistemas, hardware, software, entre outros) têm superado a média dos judiciários estadual e federal, o que garante, de certa forma, condições de trabalho superiores a muitos tribunais do país. Essas boas condições de trabalho

5 Quatro participantes não se identificaram como sendo gerentes ou não. 
podem influenciar significativamente a satisfação no trabalho, como apontam Silva e Holanda (2008), o que amenizaria, portanto, a ocorrência de estresse entre esses servidores.

Mesmo com essas boas condições de trabalho, esperavam-se níveis mais críticos de demanda no trabalho e menores níveis de controle, sobretudo pelas pesquisas já citadas em tribunais federais e também pelo modelo tecnoburocrático observado no serviço público. Todavia, os resultados apresentados indicam, de maneira geral, níveis moderados dessas variáveis entre os participantes, haja vista que apenas 30\% dos servidores percebem uma pressão alta ou baixa e controle alto ou baixo (Quadro 2). Além disso, o grupo que inspiraria maiores cuidados, ou seja, aqueles que têm uma demanda alta e um controle baixo, tem apenas doze participantes (4,52\% da amostra), conforme o Quadro 2. Nesse grupo haveria a maioria das reações psicológicas adversas que podem atingir indivíduos e organizações, tais como: decréscimo de concentração e atenção; diminuição dos poderes de observação; aumento do número de erros; aparecimento de depressão; desinteresse pelo trabalho; tendência a ignorar novas informações, resolvendo os problemas de forma cada vez mais superficial (Karasek \& Theorell, 1990; Lipp et al., 1990). Embora seja um número pequeno, urge a necessidade de verificarem-se alternativas para esses servidores.

A despeito de observarmos nas organizações públicas um modelo administrativo caracterizado pela concentração de poder, pelo formalismo técnico, pela diminuição das possibilidades de criação e de reinvenção (Osborne, 1995), os resultados encontrados, tal como exposto no Quadro 1 (fator controle) apontam que no tribunal estudado há uma relativa liberdade para decidir e agir no trabalho. Isso pode ter relação com o grau de complexidade e de instrução exigidas para as atividades nesse tribunal, já que é um órgão central para todo o Judiciário. Araújo et al. (2003) ressaltam que, embora o controle seja uma medida de autonomia, de liberdade para o uso de habilidades e qualificação, na prática, essa variável pode representar maiores responsabilidade e pressão no trabalho, o que parece não ter sido observado no presente estudo, já que a pressão foi igualmente moderada.

Outro dado a destacar é que $90 \%$ das pessoas pesquisadas afirmam ter um bom relacionamento interpessoal com colegas e chefia, conforme exposto nos Quadros 1 e 3. Embora o modelo tecnoburocrático do serviço público que, a priori, segundo Chanlat (1996), proporciona não personalização, distanciamento pessoal, os servidores pesquisados mantêm um ótimo relacionamento. Ressalta-se aqui que pode ser a ingerência política, sobretudo na distribuição e na manutenção de gratificações e de cargos em comissão, aquilo que favorece esses relacionamentos entre as pessoas, todavia, segundo Seabra (2001), está presente aí a falta de confiança entre as pessoas, o que as forçaria a criar relacionamentos mais superficiais.

Tamayo, Lima e Silva (2004), contudo, advogam que boas relações sociais abrem um espaço maior para a valorização e a ressignificação do trabalho e podem servir como moderadoras do impacto psicológico adverso do trabalho. Nesse sentido, o fato dos trabalhadores terem mais de dez anos, em média, de convivência no órgão pode também ter influenciado esses resultados, já que, quanto maior é a liberdade pessoal de expressar desejos, crenças, posições, valores pessoais no ambiente de trabalho, mais espaço há para os relacionamentos e menores são os efeitos negativos da organização precária do trabalho (Silva \& Holanda, 2008; Stoner \& Perrewé, 2007).

No que tange à diferença entre homens e mulheres, a despeito de alguns estudos demonstrarem que as mulheres, em média, desenvolvem um estresse maior que homens (Areias \& Guimarães, 2004; Lipp \& Tanganelli, 2002; Paschoal \& Tamayo, 2005), essa tendência não foi verificada na presente amostra, já que não houve diferenças significativas em nenhum dos fatores analisados. Os estudos que apontam as mulheres como tendo mais estresse no trabalho atribuem tal fato ao dilema entre família e trabalho e à pressão por produtividade para as mulheres, sobretudo no que se refere à sensação de incapacidade de administrar o tempo para realizar as atividades (Areias \& Guimarães, 2004; Rossi, 2007). 
Outros dois pontos podem também explicar essa não diferença entre homens e mulheres. O primeiro refere-se ao fato de que não apenas no tribunal pesquisado, mas em toda a administração pública as mulheres disputam equilibradamente as chances de trabalho, principalmente em razão da atitude não discriminatória do Estado nas contratações por concurso (Fontenele-Mourão, 2006). Outro ponto é a ratificação cada vez maior das políticas afirmativas em todo o setor público que garantem um espaço mais igualitário e menos discriminatório em toda a administração pública (Plano Nacional de Políticas Públicas, 2004).

A análise da pressão no trabalho indicou que os gerentes são os mais afetados, em comparação com os não gerentes, conforme Quadro 4. Isso pode estar atrelado à necessidade de maior produtividade, de adequação à estrutura organizacional e ainda à incerteza quanto ao futuro naquela função, a despeito da estabilidade que o servidor tem no cargo. Ressalta-se ainda que o fato de estarem mais sujeitos à política e aos jogos de poder da instituição, próprio do cenário público, esses gerentes colocam-se em uma situação instável, dada sua ocupação funcional, e ainda sob uma passividade de aceitação dos ditames da hierarquia da organização, o que pode influenciar decisivamente na pressão sob esses servidores. Esses dados confirmam estudos anteriores que apontaram para essa mesma tendência entre gerentes (O'Driscoll \& Beehr, 1994; Seltzer \& Numerof, 1988).

Outro ponto a destacar, conforme apresentado no Quadro 4, é que os gerentes têm maior controle sobre o trabalho. Essa liberdade, contudo, não traz maiores benefícios, já que parece inerente à posição ocupada. Ressalta-se, todavia, reverberando as afirmações de Araújo et al. (2003), que embora controle seja uma medida de autonomia e de liberdade para uso de habilidades e de qualificação, na prática, essa variável pode estar ligada também a maior responsabilidade e a pressão no trabalho. Diante disso, nesse grupo específico, liberdade no trabalho pode se constituir também como estressor e não apenas como variável de satisfação no trabalho.

No que tange ao apoio social, as variáveis gênero e cargo de gerência não parecem fundamentais para uma diferenciação na sua percepção. Seria, contudo, esperado, tal como aponta Tavares (2003), encontrar melhores relações sociais entre os gerentes, já que se constitui como um caminho para a obtenção ou a manutenção de cargos em comissão ou funções gratificadas. Todavia, essa não diferença pode ser positiva para a dinâmica organizacional, já que pode servir como moderador do estresse entre os servidores.

De maneira geral, os dados do presente estudo apontam que os itens que mais influenciam a pressão psicológica (fator demanda) são: frequência do trabalho, intensidade do trabalho e a posição ocupada pelo servidor, o que encontra eco em outros estudos (O'Driscoll \& Beehr, 1994; Seegers \& Van Elderen, 1996; Seltzer \& Numerof, 1988). Embora moderada entre os servidores pesquisados, não se pode afirmar também que exista grande liberdade para decidir sobre o processo completo do trabalho, de inovar, de criar, o que foi apontado por pesquisas anteriores como sendo estressores entre servidores do Judiciário (Biancamano, 1999; Tavares, 2003). No que concerne às relações sociais, o que mais chama atenção é que foram encontradas ótimas relações entre os servidores, mas não houve diferenças entre homens e mulheres e entre gerentes e não gerentes.

\section{Considerações finais}

Isso posto, podemos afirmar que os resultados encontrados apontaram para três direções. A primeira é que há uma moderada percepção de pressão e de liberdade no trabalho dos servidores do tribunal pesquisado. Uma segunda aponta para as ótimas relações entre colegas e chefia no trabalho, independente de gênero ou cargo ocupado. A última está 
relacionada ao fato de que a pressão no trabalho, embora moderada, é maior nos gerentes que os que não ocupam tal posição.

Desses resultados e baseados nos direcionamentos explicitados por Karasek e Theorell (1990), principalmente no que tange ao baixo número de pessoas com alto índice de pressão e baixo controle, há indícios de um baixo nível de estresse entre os servidores do tribunal pesquisado. Contudo, a relação estresse-indivíduo é apenas, como salientam Silva e Heloani (2007), um aspecto da relação mais ampla do estresse com o trabalho e a realidade sócioinstitucional. Assim, para estudos posteriores é necessária a análise de outras variáveis de caráter individual e também institucional contempladas em outros estudos e que podem repercutir nos níveis de satisfação e de estresse no trabalho dos servidores públicos e também do Judiciário, tais como: lócus de controle, níveis de depressão, relações de poder, cultura organizacional, reconhecimento no trabalho (Areias \& Guimarães, 2004; Ferris et al., 2007; Fontenele-Mourão, 2006; Nelson \& Simons, 2007; Paschoal \& Tamayo, 2005; Tavares, 2003).

Ressalta-se, contudo, tal como advogam Silva e Heloani (2007), a questão subjetiva relacionada ao estresse e ao trabalho não emerge exatamente e unicamente de dados quantitativos, já que não se estrutura como um mecanismo pré-determinado e préquantificado. Para ampliar as conclusões de futuros trabalhos, será de grande valia ter outras fontes de dados como, por exemplo, entrevistas individuais e grupais semi-estruturadas (grupos focais) e a partir daí fazer análises de natureza qualitativa. Essa abordagem integradora da metodologia de pesquisa em saúde mental e trabalho é o desejável, tendo em vista a realidade complexa e multifacetada do objeto de estudo em questão (Silva \& Heloani, 2007). Por exemplo, as entrevistas poderiam ter trazido outros conteúdos que explicassem a liberdade no trabalho, em face do modelo tecnoburocrático das organizações públicas ou, ainda, a questão do nível de relacionamento entre os servidores. As relações observadas são superficiais ou não são tão superficiais assim?

Em que pese sua limitação, os resultados aqui encontrados vão ao encontro de outros estudos com servidores públicos, mais especificamente do Poder Judiciário (Fontenelle-Mourão, 2006; Tavares, 2003). Estudos posteriores deverão buscar outras reflexões que possibilitem inspirar, manter e cultivar os valores de dedicação, de integridade, de doação, de comprometimento que deveriam permear a ideia de servir ao público. Além disso, devem principalmente possibilitar reflexões que sirvam para mudanças organizacionais que ofertem uma vivência maior de prazer e de satisfação no trabalho desses servidores públicos, sejam eles do Judiciário, ou não.

\section{Referências}

Alves, M. G. M., Chor, D., Faerstein, E., Lopes, C. S. \& Werneck, G. L. (2004). Versão resumida da "job estresse scale": adaptação para o português. Revista de Saúde Pública, 38 (2), 164-171.

Areias, M. E. Q. \& Guimarães, L. A. M. (2004). Gênero e estresse em trabalhadores de uma universidade do estado de São Paulo. Psicologia em Estudo, 9 (2), 255-262.

Araújo, T., Graça, C. \& Araújo, E. (2003). Estresse ocupacional e saúde: contribuições do Modelo DemandaControle. Ciência e Saúde Coletiva, 8 (4), 991-1003.

Barcelos Silva, I. (2004). A motivação de juízes e servidores como técnica de eficiência. Revista do Centro de Estudos Judiciários, 24, 43-48.

Bellusci, S. M. \& Fischer, F. M. (1999). Envelhecimento funcional e condições de trabalho em servidores forenses Revista de Saúde Pública, 33 (6), 602-609.

Biancamano, M. (1999). O poder judiciário e o movimento da qualidade total: aspectos determinantes na implantação do PGQJ em um estudo exploratório. Dissertação de Mestrado, Universidade Federal do Rio Grande do Sul, Porto Alegre. 
Bogg, J. \& Cooper, C. (1995). Job satisfaction, mental health, and occupational stress among senior civil servants. Human Relations, 48 (3), 327-341.

Chanlat, J. F. (1996). Modos de gestão, saúde e segurança no trabalho. In E. P. B. Davel \& J. G. M. Vasconcelos (Orgs.), Recursos humanos e subjetividade (pp. 118-128). Petrópolis: Vozes.

Durand, J. C. \& Beltrão, V. E. (1994). Recensear funcionários públicos: uma necessidade. Revista do Servidor Público, 118 (2), 185-198.

Ferris, G. R., Brouer, R. L., Laird, M. D. \& Hochwarter, W. A. (2007). As consequências da política organizacional como estressor no local de trabalho. In A. M. Rossi, P. L. Perrewé \& S. L. Sauter (Orgs.), Estresse e qualidade de vida no trabalho: perspectivas atuais da saúde ocupacional (pp. 156-166). São Paulo: Atlas.

Fontenele-Mourão, T. M. (2006). Mulheres no topo da carreira: flexibilidade e persistência. Brasília: Secretaria Especial de Políticas para as Mulheres.

Garbin, A. C. \& Tavares, D. S. (2000). A relação saúde mental e trabalho dos funcionários públicos do setor judiciário. Anais do VI Congresso Brasileiro de Saúde Coletiva: Sujeito Ação em Saúde Coletiva (p. 513). Salvador.

Hegedus, A. (1996). Burocracia. In: W. Outhwaite \& T. Bottomore (Orgs.), Dicionário do pensamento social do século $\chi \chi$. Rio de Janeiro: Zahar.

Karasek, R. A. \& Theorell, T. (1990). Healthy work: stress, productivity and the reconstruction of working life. New York: Basic Books.

Lipp, M. N., Romano, A. S. P. F., Covolan, M. A. \& Nery, M. J. G. S. (1990). Como enfrentar o estresse. São Paulo: Ícone.

Lipp, M. E. N. \& Tanganelli, M. S. (2002). Estresse e qualidade de vida em magistrados da Justiça do Trabalho: diferenças entre homens e mulheres. Psicologia Reflexão e Crítica, 15 (3), 537-548.

Minari, M. R. T. (2007). Estresse em servidores públicos do Instituto Nacional do Seguro Social de Campo Grande, MS. Dissertação de Mestrado, Universidade Católica Dom Bosco, Campo Grande.

Muniz, J. A. \& Abreu, A. R. (1999). Técnicas de amostragem. Lavras: Editora da Universidade Federal de Lavras.

Nelson, D. L. \& Simmons, B. L. (2007). Eustresse e esperança no trabalho: mapeando a jornada. In A. M. Rossi, P. L. Perrewé \& S. L. Sauter (Orgs.), Estresse e qualidade de vida no trabalho: perspectivas atuais da saúde ocupacional (pp. 125-138). São Paulo: Atlas.

O'Driscoll, M. \& Beehr, T. A. (1994). Supervisor behaviors, role stressors and uncertainty as predictors of personal outcomes for subordinates. Journal of Organizational Behavior, 5, 141-155.

Osborne, D. (1995). Reinventando o governo: como o espírito empreendedor está transformando o setor público. Brasília: MH Comunicações.

Paschoal, T. \& Tamayo, A. (2005). Impacto dos valores laborais e da interferência família-trabalho no estresse ocupacional. Psicologia: Teoria e Pesquisa, 21 (2), 173-180.

Plano Nacional de Políticas para as Mulheres (2004). Brasília: Secretaria Especial de Políticas para as Mulheres.

Rossi, A. M. (2007). Estressores ocupacionais e diferenças de gênero. In A. M. Rossi, P. L. Perrewé \& S. L. Sauter (Orgs.), Estresse e qualidade de vida no trabalho: perspectivas atuais da saúde ocupacional (pp. 9-18). São Paulo: Atlas.

Sadek, M. T. A. \& Arantes, R. B. (1994). A crise do judiciário e a visão dos juízes. Dossiê Judiciário. Revista USP, $21,34-45$.

Seabra, S. N. (2001). A nova administração pública e mudanças organizacionais. Revista de Administração Pública, 35 (4), 19-43.

Seegers, G. \& Van Elderen, T. (1996). Examining a model of stress reactions of bank directors. European Journal of Psychological Assessment, 12 (3), 212-223.

Seltzer, J. \& Numerof, R. (1988). Supervisory leadership and subordinate burnout. Academy of Management Journal, 31, 439-446.

Silva, E. P. \& Heloani, R. (2007). Aspectos teóricos e metodológicos da pesquisa em saúde mental e trabalho: reflexões a partir de uma análise comparativa do estresse em jornalistas e guardas municipais. Cadernos de Psicologia Social do Trabalho, 10 (1), 105-120.

Silva, R. R. \& Holanda, A. (2008). A vivência de prazer e sofrimento no trabalho de líderes protestantes. Estudos de Psicologia, 25 (3), 375-383. 
Stacciarini, J. M. \& Tróccoli, B. (2002). Estresse Ocupacional. In A. M. Mendes, L. O. Borges \& M. C. Ferreira (Orgs.), Trabalho em transição. Saúde em risco (pp. 187-205). Brasília: Editora da Universidade de Brasília.

Stoner, J. \& Perrewé, P. L. (2007). As consequências do humor deprimido no trabalho: a importância do apoio dos superiores. In A. M. Rossi, P. L. Perrewé \& S. L. Sauter (Orgs.), Estresse e qualidade de vida no trabalho: perspectivas atuais da saúde ocupacional (pp. 91-103). São Paulo: Atlas.

Tamayo, A., Lima, D. \& Silva, A. V. (2004). Clima organizacional e estresse no trabalho. In A. Tamayo (Org.), Cultura e saúde nas organizações (pp. 77-101). Porto Alegre: Artmed.

Tavares, D. S. (2003). O sofrimento no trabalho entre servidores públicos: uma análise psicossocial do contexto de trabalho em Tribunal Judiciário Federal. Dissertação de Mestrado, Universidade de São Paulo, São Paulo.

\section{Endereço para correspondência}

rogerio@psicologorogerio.com.br

Recebido em: 28/08/2008

Revisado em: 25/11/2008

Aprovado em: 20/12/2008 